\title{
Molecular Markers for Metabolic Adaptation in Dairy Cows: SNAI2 Gene Variations
}

\author{
S.V. Vasudhar Bhat, M. Shynu, P.D. Divya, Akshatha G. Desai', G.H. Akhil ${ }^{1}$
}

10.18805/ajdfr.DR-1763

\begin{abstract}
Background: Healthy transition from non-lactating pregnant state to non-pregnant lactating state is an important in the profitability of dairying. Though feeding and managemental practices play an important role in the adaptation to transition, animals kept on similar feeding and management exhibit differences in adaptation indicating an underlying genetic cause. In the present study, the sequence of gene SNA12, which is considered to have an effect on metabolic adaptability has been compared among animals with apparently varying adaptability, as indicated by their $\beta$-hydroxy butyric acid (BHBA) concentration.

Methods: During the period from August 2018 to May 2019, blood was collected and serum was separated from 30 pregnant cross bred (belonging to Sunandini genetic group of cross bred cattle of Kerala) dairy cows at fortnightly intervals from four weeks before the predicted day of parturition until four weeks after parturition. Concentration of BHBA was determined. Based on BHBA concentration the animals were sorted into two groups (High BHBA and low BHBA) using cluster analysis. Blood was collected, DNA extracted and SNAI2 gene amplified using custom synthesised primers. Amplicons from representative animals of each group were sequenced. The sequences obtained were aligned and compared using clustal- $\omega$.

Result: The comparison of the sequence of SNAI2 gene amongst the animals having high BHBA and those with low BHBA revealed two variations between the groups, one at promoter region, $61 \mathrm{bp}$ upstream to the gene and other was at exonic region at $1560 \mathrm{bp}$. In silico structural analysis revealed difference in protein structure. The changes observed in the gene SNAI2 between the sets of animals grouped based on BHBA has to be studied on a larger population to ascertain the suitability of them being used as markers of genetic selection for metabolic adaptability, which in turn can increase the profitability of dairying.
\end{abstract}

Key words: Metabolic adaptation, SNAI2, Transition period.

\section{INTRODUCTION}

The period from three weeks before parturition to three weeks after parturition in dairy cows is defined as transition period. The word transition refers to the important physiological, metabolic and nutritional changes occurring during this period of time (Block, 2010). The transition from of pregnancy to lactation is characterized by metabolic stress because of the sudden increase in the energy demand to initiate milk secretion, with slower rise in dry matter intake. When the intake fails to meet the increased demand, animals are forced into a state of negative energy balance (NEB), especially the high yielding dairy cows (Lean et al., 2013). In order to compensate this negative energy balance, animal undergoes several metabolic adaptations like mobilization of body fat as non-esterified fatty acids (NEFA) which gets converted into $\beta$-hydroxy butyric acid (BHBA) which can be utilized by an extra-hepatic tissues. Hence NEFA and BHBA could be good indicators of the extent of lipid mobilizations and magnitude of NEB (Adewuyi et al., 2005). Successful adaptation to the huge metabolic changes associated with transition from pregnancy to lactation is very important in economic dairying.

Even when the animals are maintained under similar feeding and managemental conditions, they exhibit variations in adaptation indicating an underlying genetic effect. SNAI2, a gene present on chromosome 14 is reported to be influenced successful adaptation to transition
Department of Veterinary Biochemistry, College of Veterinary and Animal Sciences, Mannuthy, Thrissur-680 651, Kerala, India.

${ }^{1}$ Veterinary Officer, Department of Animal Husbandry, Government of Karnataka, Bengaluru-560 001, Karnataka, India.

Corresponding Author: M. Shynu, Department of Veterinary Biochemistry, College of Veterinary and Animal Sciences, Pookode, Wayanad-673 576, Kerala, India. Email: shynu@kvasu.ac.in

How to cite this article: Vasudhar Bhat, S.V., Shynu, M., Divya, P.D., Desai, A.G. and Akhil, G.H. (2021). Molecular Markers for Metabolic Adaptation in Dairy Cows: SNAI2 Gene Variations. Asian Journal of Dairy and Food Research. DOI: 10.18805/ajdfr.DR-1763.

Submitted: 17-06-2021 Accepted: 06-08-2021 Online: 09-09-2021

(Ha et al., 2015). With this background, the present study was conducted to discover variations between the metabolically challenged and robust group of animals by comparing sequence of SNAI2 gene.

\section{MATERIALS AND METHODS}

The study was conducted in 30 clinically healthy pregnant cross bred dairy cows (belonging to Sunandini genetic group of cross bred cattle of Kerala) in second to third parity, four to seven years of age and an average production of seven to nine kilograms of milk/day in the previous calving, maintained at University Livestock Farm and Fodder 
Research and Development Scheme, Kerala Veterinary and Animal Sciences University, Mannuthy, during the period from August 2018 to May 2019.

Blood samples $(5 \mathrm{ml})$ were collected at fortnightly intervals from four weeks before the predicted calving until four weeks after calving. Serum concentrations of BHBA were measured using kits supplied by Randox Laboratories Ltd. and the analysis was done in semiautomatic analyzer (Hospitex Master T). Animals were grouped into two by cluster analysis, based on their serum BHBA levels, as high BHBA (BHBA-H) and low BHBA (BHBA-L) groups.

DNA was extracted from blood collected from representative animals of each group by standard phenolchloroform method (Sambrook and Russell, 2001). Primers were designed from published Bos taurus gene sequences (ENSBTAG00000013227), available in Ensembl using Primer3 software for amplification of SNAI2 gene. The gene sequence was 4802 bp long and was amplified using five sets of overlapping primers (Table 1). The PCR reaction mixture and cycling conditions used are given in Table 2 and Table 3, respectively.

Pooled samples of amplicons of representative animals of each group were sequenced in both directions in an automated sequencer using Sanger's dideoxy chain termination method at AgriGenom Labs Pvt. Ltd., Cochin. The sequence obtained was analyzed using various bioinformatics tools. The nucleotide sequence obtained was subjected to BLAST analysis (http://blast.ncbi.nlm.nih.gov/ blast) to confirm that sequences were of SNAI2 gene. The sequences of the two groups were then aligned using MegAlign and analyzed using Clustal-w (http:// www.ebi.ac.uk/Tools/msa/clustalo/).

\section{RESULTS AND DISCUSSION}

The mean BHBA concentration of the animals estimated at fortnightly intervals from four weeks before the predicted day of parturition until four weeks after parturition were $0.599 \pm 0.038 \mathrm{mmol} / \mathrm{L}, 0.616 \pm 0.031 \mathrm{mmol} / \mathrm{L}, 0.645 \pm 0.027$ $\mathrm{mmol} / \mathrm{L}$ and $0.718 \pm 0.037 \mathrm{mmol} / \mathrm{L}$, respectively (Vasudhar et al., 2020). Animals were then grouped into two by cluster analysis into high and low BHBA groups. Significant variation in the concentration of BHBA between the animals in a homogenous group kept under similar feeding and managemental conditions point towards individual variations between the animals to adapt. A high BHBA concentration is indicative of negative energy balance and consequent ketonemia (Bezerra et al., 2014).

SNAI2 gene is present in chromosome 14 comprising of three exons encoding the zinc finger protein SNAI2, which has 268 amino acids. SNAI2 protein is expressed in the nucleus and functions as a transcriptional repressor which controls both activator dependent and basal transcription (Hemavathy et al., 2000). The repression activity depends on C-terminal DNA-binding zinc fingers and the $\mathrm{N}$-terminal repression domain (https://myhits.isb-sib.ch).
A fragment of about 4,783 bp on chromosome 14 was sequenced, which included the upstream, downstream, intronic and exonic sequences of the SNAI2 gene. The sequence results were obtained for the representative pools from both BHBA-H and BHBA-L groups. On comparison of sequences using the bioinformatics tools (Clustal $\omega$ ) two changes were observed between the groups (Fig 1). The BHBA-H group animals had " $C$ " and BHBA- $L$ group animals had "T" at 61 bp which is upstream to the SNAI2 gene. The change, which is a transition, being present in the upstream promoter region of the gene could have an effect on the expression of the gene. Analysis of the promoter region predicted two $\mathrm{CpG}$ islands $399 \mathrm{bp}$ and 129 bp long extending

Table 1: Primer sequences for amplification of SNAI2.

\begin{tabular}{llr}
\hline Primer & $\begin{array}{l}\text { Primer sequence } \\
\left(5^{\prime}-3^{\prime}\right)\end{array}$ & $\begin{array}{r}\text { Product } \\
\text { size }(\mathrm{bp})\end{array}$ \\
\hline SNAI2-1F & 5'-TTCTTTCAAGCCCCGATGTTA - 3' & $962 \mathrm{bp}$ \\
SNAI2-1R & 5'-GCCAGCTCAGAGTGTGGAA- 3' & \\
SNAI2-2F & 5'-GTCCTTCCTCAGATCGTTCG - 3' & $1095 \mathrm{bp}$ \\
SNAI2-2R & 5'-TCCTTGCAGTAACCAGGGTCT - 3' & \\
SNAI2-3F & 5'-ACGCACACCTTACCTTGTGTC -3' & $1077 \mathrm{bp}$ \\
SNAI2-3R & 5'- CCTCAGGTTGGACCTGTCTG - 3' & \\
SNAI2-4F & 5'-GGAGAAGCCTTTTTCCTGCTC - 3' & $1177 \mathrm{bp}$ \\
SNAI2-4R & 5'-TTTCACAAGTCTTCAGGTTGTTT-3' & \\
SNAI2-5F & 5'-TGATTGAATGAGTTTTGTATGAAAGTG-3' & $726 \mathrm{bp}$ \\
SNAI2-5R & 5'-TCTTAGCCATGCACCTGTCA -3' & \\
\hline
\end{tabular}

Table 2: PCR reaction mixture used to amplify SNAI2 gene.

\begin{tabular}{lc}
\hline Item & Quantity $(\mu \mathrm{L})$ \\
\hline Template DNA & 1.0 \\
10 X PCR buffer & 5.0 \\
dNTP's (10 mM) & 1.0 \\
Forward Primer (10 pmoles $/ \mu \mathrm{L})$ & 2.0 \\
Reverse Primer (10 pmoles $/ \mu \mathrm{L})$ & 2.0 \\
Taq polymerase & 1.0 \\
Nuclease free water & 36.0 \\
Total & 50.0 \\
\hline
\end{tabular}

Table 3: Cycling conditions to amplify SNAI2 gene.

\begin{tabular}{|c|c|c|c|}
\hline \multicolumn{2}{|c|}{ Step } & \multirow[t]{2}{*}{ Temperature } & \multirow{2}{*}{$\frac{\text { Duration }}{3 \mathrm{~min} .}$} \\
\hline Initial denaturation & $95^{\circ} \mathrm{C}$ & & \\
\hline Denaturation & $95^{\circ} \mathrm{C}$ & & $1 \mathrm{~min}$ \\
\hline \multicolumn{4}{|l|}{ Annealing } \\
\hline SNAI2-1 & $61.6^{\circ} \mathrm{C}$ & & \\
\hline SNAI2-2 & $60.7^{\circ} \mathrm{C}$ & & \\
\hline SNAI2-3 & $67.6^{\circ} \mathrm{C}$ & & $30 \mathrm{sec}$. \\
\hline SNAI2-4 & $56.4^{\circ} \mathrm{C}$ & & \\
\hline SNAI2-5 & $61.8^{\circ} \mathrm{C}$ & & \\
\hline Extension & $72^{\circ} \mathrm{C}$ & & $1 \mathrm{~min}$. \\
\hline Final extension & $72^{\circ} \mathrm{C}$ & & $5 \mathrm{~min}$. \\
\hline Hold & $4^{\circ} \mathrm{C}$ & “ & \\
\hline
\end{tabular}

Steps 2 to 4 were repeated for 34 cycles 


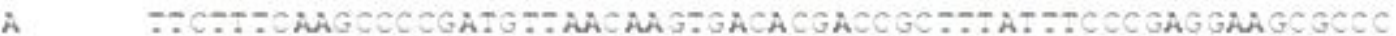

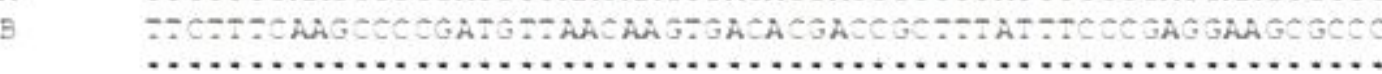

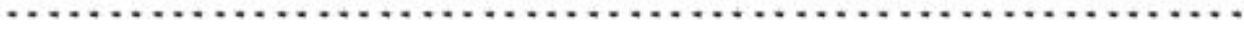

A EcCACCCCCAGCCGCCGGGACACGARGCGCAZCCCCAGCGCGCGAAGCGGACGGGTCZC

B ECTACCCCCAGCCGCCGGGACACGAMGCGCA:CCCCAGCGCGCGAAGCGGACGGGTCTC

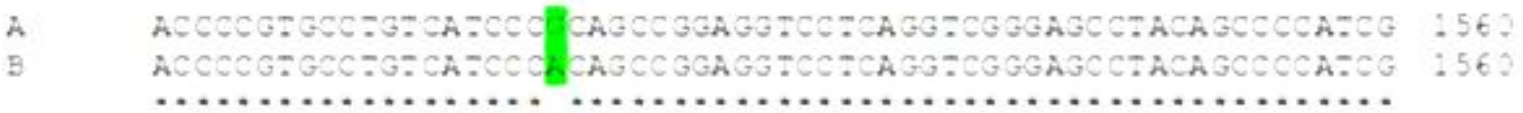

A G transition $\underline{a} 1520 \mathrm{bp}$

Fig 1: Clustal $\omega$ (MSA) for comparison of SNAI2 gene; A: BHBA-H, B: BHBA-L.

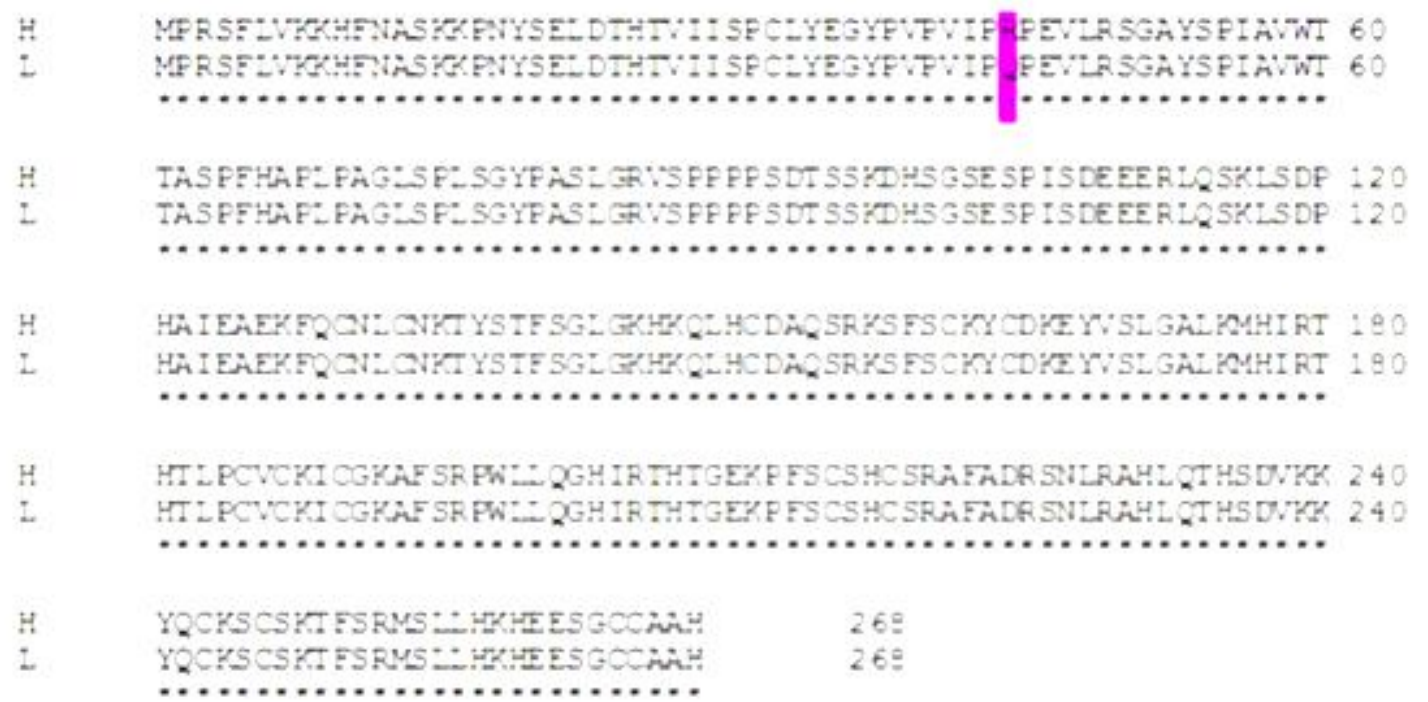

Fig 2: MSA of the predicted protein sequence of BHBA-H and BHBA-L animals. H: BHBA-H; L: BHBA-L.

from $21 \mathrm{bp}$ to $419 \mathrm{bp}$ and $526 \mathrm{bp}$ to $654 \mathrm{bp}$, respectively. The change in the $\mathrm{CpG}$ island could be of significance in gene expression. The change at the promoter region could have been bring about change in expression of the gene which needs to be confirmed by expression studies.

The second change was observed at $1560 \mathrm{bp}$, BHBA$\mathrm{H}$ group animals had "G" whereas BHBA-L group animals had " $A$ ". This change was located at the exonic region which could be due to the change in amino acid sequence. The change brought about variation in amino acid at 44th position between the two groups (Fig 2).

In silico structural analysis revealed difference in the protein structure. The variation in sequence brought about $2.61 \%$ change in alpha helical content and nearly $1.86 \%$ change in the content of beta turn.

\section{CONCLUSION}

Healthy metabolic adaptability to transition from pregnant non lactating state to a non- pregnant lactating state is essential for profitable dairying. Proper management and feeding influence metabolic adaptation and transition (Overton and Waldron, 2004), but even when animals are maintained under even managemental and feeding conditions the animals have shown individual variations to adaptation as indicated by the concentration of BHBA, pointing towards an underlying genetic cause. SNAI2 gene is reported to influence metabolic adaptation and so the variations in the sequence of the gene in metabolically robust and challenged groups were analyzed. Though there were changes in two nucleotide two variations between the groups, one at promoter region, $61 \mathrm{bp}$ upstream to the gene and other was at exonic region at $1560 \mathrm{bp}$, the effect of these changes in metabolic adaptability need to be determined in a large population. The changes observed in the genes between the set of animals grouped based on BHBA concentration has to be studied on a larger population 
to ascertain the suitability of them being used as markers for selecting animals on the basis of metabolic adaptability, which in turn can increase the profitability of dairying.

\section{REFERENCES}

Adewuyi, A.A., Gruys, E. and Van Eerdenburg, F.J.C.M. (2005). Non esterified fatty acids (NEFA) in dairy cattle. A review. Veterinary Quarterly. 27(3): 117-126.

Bezerra, L.R., de Oliveira Neto, C.B., de Araujo, M.J., Edvan, R. L., de Oliveira, W.D. and Pereira, F.B. (2014). Major metabolic diseases affecting cows in transition period. International Journal of Biology. 6(3): 85-94.

Block, E. (2010). Transition cow research-what makes sense today. In: Proceedings High Plains Dairy Conference, $10^{\text {th }}$ to $12^{\text {th }}$ March, 2010, Amarillo, Texas (pp. 75-98).

Ha, N.T., Gross, J.J., van Dorland, A., Tetens, J., Thaller, G., Schlather, M. and Simianer, H. (2015). Gene-based mapping and pathway analysis of metabolic traits in dairy cows. PloS One. 10(3): e0122325.
Hemavathy, K., Guru, S.C., Harris, J., Chen, J.D. and Ip, Y.T. (2000). Human Slug is a repressor that localizes to sites of active transcription. Molecular and Cellular Biology. 20(14): 5087-5095.

Lean, I.J., Van Saun, R. and DeGaris, P.J. (2013). Energy and protein nutrition management of transition dairy cows. Veterinary Clinics: Food Animal Practice. 29(2): 337-366.

Overton, T.R. and Waldron, M.R. (2004). Nutritional management of transition dairy cows: strategies to optimize metabolic health. Journal of Dairy science. 87: E105-E119.

Sambrook, J. and Russell, D.W. (2001). Cold Spring Harbor Laboratory. Molecular cloning: A Laboratory Manual. Cold Spring Harbor, N.Y: Cold Spring Harbor Laboratory, 2100p

Vasudhar B, S.V., Shynu, M., Akshatha, G.D. and Akhil, G.H. (2020). Single nucleotide variations in DNAJC30 gene: A potential marker for metabolic adaptation in transition dairy cows. Journal of Indian Veterinary Association, Kerala (JIVA). 18(2): $20-23$. 